ic tests, 41 per cent had never contacted either the Food and Drug Administration (FDA) or their own institutional review board (IRB). Similarly, out of 140 academic laboratories, more than a quarter had never contacted either organization.

Holtzman pointed out that organizations that provide services and make their own probes and primers must ask for review from their IRB, and in some cases must also obtain an investigational device exemption from the FDA. External review did increase among the 14 biotechnology companies offering services using their own products. But almost 30 per cent still had never contacted a regulatory body.

The study also showed that academic laboratories were less likely than companies to have undergone any external quality review. Out of about a hundred non-profit laboratories providing molecular genetic services, 16 had not registered as required under the federal Clinical Laboratory Improvement Amendments or participated in any proficiency testing. At least one geneticist said he felt his published discoveries were sufficient to demonstrate the quality of his laboratory, and that certification was unnecessary, says Holtzman.

Some participants at the Minneapolis meeting claimed that the survey was too imprecise to demonstrate the size of the problems described. They criticized the results for not indicating how far along the development process a company had progressed before approaching any regulatory body. Stephen Goodman, of the University of Colorado Health Sciences Center in Denver and treasurer of the American Society of Human Genetics, said that a laboratory was not necessarily in the wrong if it had not approached its institutional review boards. "You really need to know the research they're doing," he said. Sally Lehrman

\title{
NASA staff face shake-up as panel backs privatization bid
}

Washington. The concept of privately run "science institutes" has been endorsed in an internal study at the US Aeronautics and Space Administration (NASA). The institutes would conduct a significant amount of the agency's research and - presumably inherit many of its staff scientists.

But the plan is still vague, and fraught with legal and administrative problems. Scientists inside and outside the agency are reserving judgement until they hear more about it. "We're all still waiting to see the details," says Anneila Sargent of the California Institute of Technology, chair of NASA's Space Science Advisory Council, which will be briefed on the plan next week.

The idea of science institutes surfaced last winter during a series of soul-searching reviews intended to lead to a new, leaner space agency (see Nature 374, 107; 1995).

Initially, 'privatizing' NASA's science was seen as a way to cut the agency's operational overheads. But by the time Daniel Goldin, the NASA administrator, announced a plan to restructure the agency in May, the institutes were no longer being touted as moneysavers but as a way to enhance the quality of NASA research by strengthening its ties with industry and the academic world.

A team led by Al Diaz, the agency's deputy science chief, spent much of the summer touring NASA and non-NASA centres, formulating a plan of the way in which the institutes would be structured. Diaz is now beginning to go public with his group's findings, briefing officials in Congress and the White House, as well as NASA advisory

\section{Infrared observatory prepares for lift-off}

Munich. The Infrared Space Observatory (ISO) is to be launched from Kourou, French Guiana, by the European Space Agency (ESA) this weekend. The observatory's RitcheyChretien-type telescope (right), which has a focal length of 9 metres and an aperture of $\mathbf{0 . 6}$ metres diameter, will turn its sights on some of the quarterof-a-million point sources of infrared radiation catalogued by IRAS, the joint UK/Dutch/US Infrared Astronomical Satellite, which scanned the infrared sky in 1983.

ISO's high sensitivity will give astrophysicists the opportunity to glean fundamental information about the formation of stars and solar systems. ISO will also search for the Universe's 'missing mass' - the difference between the theoretical mass of

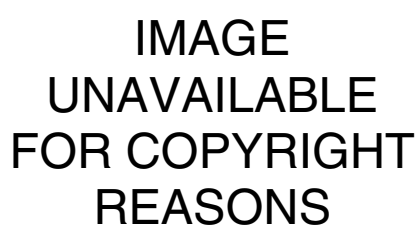

the Universe deduced from gravitational calculations and what can be seen in the visible light range. groups, on the plan's broad outlines.

The new institutes, selected through competitive bidding, would receive their core funding from NASA; existing NASA centres would provide "services and support" although what that means has not yet been spelled out. Not surprisingly, the institutes would be encouraged to seek outside funding and become as self-sufficient as possible. To that end, they would retain intellectual property from any research.

The Diaz team began and ended with the same list of 11 institutes proposed by another NASA review team earlier this year. According to Diaz himself, it agreed that a biomedical research institute affiliated with the Johnson Space Center (JSC) in Houston should be the first one established, perhaps by early next year.

The rest are in "various stages of readiness", he says. Three - a Goddard Institute for Space Studies in New York, a Global Hydrology and Climate Center at the Marshall Space Flight Center in Alabama, and an Astromaterials Institute at Johnson could be created by simply modifying existing relationships.

Three others need to be "further defined", according to the Diaz report. These are institutes for microgravity and space science at Marshall and an Atmospheric Sciences Institute at the Langley Research Center in Virginia. And two more - a space power and propulsion institute at the Lewis Research Center in Cleveland, Ohio, and the National Space Science Data Center, at Maryland's Goddard Space Flight Center should be reconsidered altogether, because "the model developed for other institutes is not applicable" to them.

The two remaining institutes - for astrobiology (Ames Research Center) and microgravity studies (Lewis) - are also problematic, as Congress might have to pass new laws to clear up thorny employment issues. These include the transfer of pensions and other benefits for government scientists who move to the private sector.

Another issue to be resolved concerns restrictions on where and how ex-government employees can work. NASA officials have already begun talking to congressional committees about passing "legislative relief". Without it, NASA scientists could lose benefits if they move to an institute.

But Diaz points out that the institutes should not be seen as a placement service for redundant government scientists. "The staffing of these institutes ought to be totally at the discretion of the institute management," he says, adding that NASA should not play a role in choosing who gets hired.

Tony Reichhardt 